\title{
Multicriteria analysis in hazards assessment in Libya
}

\author{
Martina Zeleňáková ${ }^{1}$, Ibrahim Gargar ${ }^{1}$, Pavol Purcz ${ }^{2}$ \\ ${ }^{1}$ Technical University of Košice \\ Civil Engineering Faculty, Institute of Environmental Engineering \\ e-mail: martina.zelenakova@tuke.sk, ebrahimkhalifa1@gmail.com \\ ${ }^{2}$ Technical University of Košice \\ Civil Engineering Faculty, Institute of Construction Technology and Management \\ e-mail: pavol.purcz@tuke.sk
}

\begin{abstract}
Environmental hazards (natural and man-made) have always constituted problem in many developing and developed countries. Many applications proved that these problems could be solved through planning studies and detailed information about these prone areas. Determining time and location and size of the problem are important for decision makers for planning and management activities. It is important to know the risk represented by those hazards and take actions to protect against them. Multicriteria analysis methods - Analytic hierarchy process, Pairwise comparison, Ranking method are used to analyse which is the most dangerous hazard facing Libya country. The multicriteria analysis ends with a more or less stable ranking of the given alternatives and hence a recommendation as to which alternative(s) problems should be preferred. Regarding our problem of environmental risk assessment, the result will be a ranking or categorisation of hazards with regard to their risk level.
\end{abstract}

Key words: environmental risk, multicriteria analysis, Analytic hierarchy process, Pairwise comparison, Ranking method

\section{Introduction}

Environmental problems have the potential to cause fatalities, displacement of people and damage to the environment. Libya as other countries worldwide is facing environmental hazards. The objective of this paper is to increase awareness of hazards and risks with aim to prevent their occurrence, to limit their impacts and minimize its losses.

Multicriteria analysis is well suited for conflict resolution as many problems incorporate a wide range of highly complex information that otherwise would be overwhelming for manual aggregation or subjective to high levels of human error [1].

The main aim of this study is to determine dangerous hazards facing Libya using selected consecutive factors affected those hazards. 


\section{Study area}

Libya occupies a part of northern Africa (Fig. 1). It is bounded in the east by Egypt, in the west by Tunisia and Algeria, by Mediterranean Sea in the north, and by Sudan, Chad, and Niger in the south.

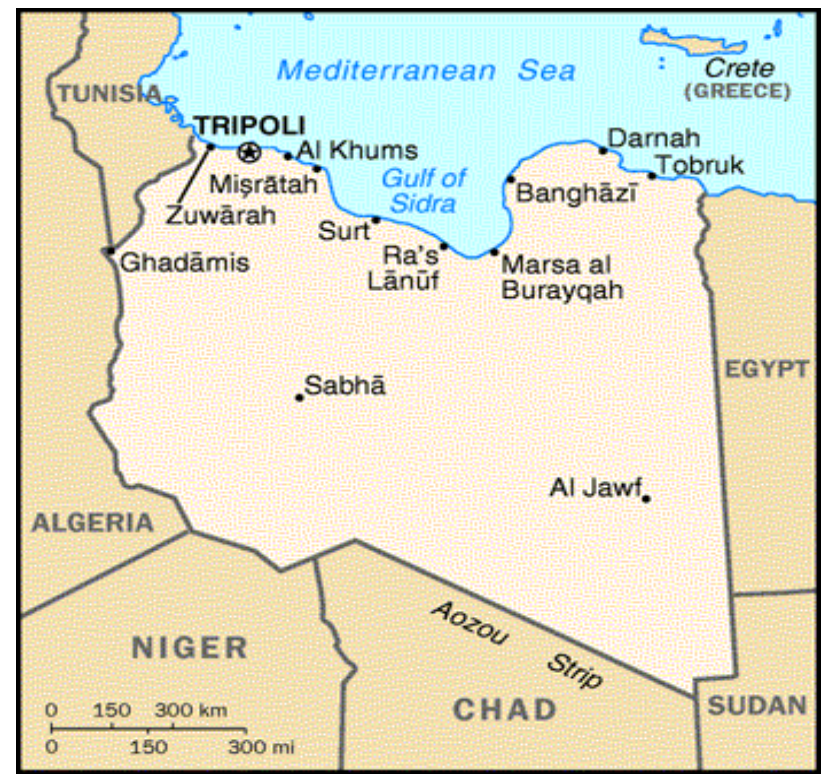

Figure 1: Map of Libya [3]

Total area of Libya is about 1.76 million $\mathrm{km}^{2}$. More than $95 \%$ of country is desert. The cultivable areas are estimated at 3.8 mill. ha or slightly over $2 \%$ of the total area, while the irrigation areas in all Libya were estimated at 400,000 ha. The fertile lands of Jifara Plain in the northwest, Jebal Al-Akhdar in the northeast and the coastal plain east of Sirt receive sufficient precipitation to support agriculture. As a result, more than $90 \%$ of Libyan population resides there [2].

\section{Multicriteria analysis}

Decision analysis looks at the paradigm in which an individual decision maker (or decision group) contemplates a choice of action in an uncertain environment. One of possible approaches for identifying environmental hazards is to use multicriteria analysis methods Different multicriteria analysis methods is available in the literature $[1,4,5,6,7,8]$.

Multicriteria analysis (MCA) as apart of decision analysis is designed to help the individual make a choice among a set of pre-specified alternatives. The decision making process relies on information about the alternatives. The quality of information in any decision situation can run the whole gamut from scientifically derived hard data to subjective interpretations, from certainty about decision outcomes [5]. 
Multicriteria analysis has many advantages [6]:

- It is open and explicit;

- The choice of objectives and criteria that any decision making group may make are open to analysis and to change if they are felt to be inappropriate;

- Scores and weights, when used, are also explicit and are developed according to established techniques. They can also be cross referenced to other sources of information on relative values, and amended if necessary;

- Performance measurement can be subcontracted to experts, so need not necessarily be left in the hands of the decision making team itself.

Disadvantages of multicriteria analysis are [6]:

- There is a possibility that community preferences will be determined, not by the community, but by a single decision-maker, without consultation with the community;

- Although MCA does not necessarily require quantitative or monetary data, the information requirements to compile the effects table and derive the weights can, nevertheless, be considerable;

- Although the weights used in the process are explicit weights, the analyst may unintentionally introduce implicit weights during the evaluation process. If not properly used MCA has the potential to become a 'black box', producing results that cannot be explained.

Multicriteria analysis is an approach for choosing from among a set of alternatives when there are multiple objectives/criteria. The selection of criteria that has spatial reference is an important step in multicriteria decision analysis [9]. The criteria used in this study were selected due to their relevance in study of natural as well as man-made hazards assessment in Libya. Criteria and their weights are entering into the decision making process as "fixed" data, there can users change under certain conditions. Each expert shall have the right to exercise its criterion in defining its relationship to the problem and determine whether a higher value criterion has a positive or negative effect. On the set of criteria we can apply the following requirements:

- complete set of criteria,

- minimize the scope of a set of criteria,

- eliminate duplication,

- possibility of creating a tree measurability criteria (each criterion must allow alternative safeguard against the consequences of this criterion or quantitative or qualitative probability distribution.

Multicriteria analysis is a decision-making tool developed for complex problems. MCA often requires the decision maker to provide qualitative assessments for determining the performance of each alternative with respect to each criterion and the relative importance of the evaluation criteria with respect to the overall objective of the problem. In this paper three of MCA methods are used for evaluation the most dangerous hazard facing Libya country. 


\subsection{Analytic hierarchy process}

The Analytic hierarchy process (AHP) is a structured technique for organizing and analyzing complex decisions. Based on mathematics and psychology, it was developed by Thomas L. Saaty in the 1970s and has been extensively studied and refined since then. It has particular application in group decision making, and is used around the world in a wide variety of decision situations, in fields such as government, business, industry, healthcare, and education. Rather than prescribing a "correct" decision, the AHP helps decision makers find one that best suits their goal and their understanding of the problem. It provides a comprehensive and rational framework for structuring a decision problem, for representing and quantifying its elements, for relating those elements to overall goals, and for evaluating alternative solutions [10]. AHP allows users to assess the relative weight of multiple criteria (or multiple alternatives against a given criterion) in an intuitive manner.

To make a decision in an organised way to generate priorities we need to decompose the decision into the following steps [9]:

- Define the problem and determine the kind of knowledge sought.

- Structure the decision hierarchy from the top with the goal of the decision, then the objectives from a broad perspective, through the intermediate levels (criteria on which subsequent elements depend) to the lowest level (which usually is a set of the alternatives).

- Construct a set of Pairwise comparison matrices. Each element in an upper level is used to compare the elements in the level immediately below with respect to it.

- Use the priorities obtained from the comparisons to weigh the priorities in the level immediately below. Do this for every element. Then for each element in the level below add its weighed values and obtain its overall or global priority. Continue this process of weighing and adding until the final priorities of the alternatives in the bottom most level are obtained.

The major innovation of AHP was the introduction of Pairwise comparison.

\subsection{Pairwise comparison}

Pairwise comparison (PC) is a method that is informed by research showing that when quantitative ratings are unavailable, humans are still adept at recognizing whether one criterion is more important than another [4 \& 12].

Generally refers to any process of comparing entities in pairs to judge which of each entity is preferred, or has a greater amount of some quantitative property. The method of Pairwise comparison is used in the scientific study of preferences, attitudes, voting systems, social choice, public choice, and multivalent systems.

The weight of criteria $W_{\mathrm{j}}$ is calculated using the following equation (1) and (2).

$$
W_{\mathrm{j}}=\frac{n_{\mathrm{j}}}{N}
$$




$$
N=\frac{k}{2} \cdot(k-1)
$$

Where:

$W_{\mathrm{j}}$ - weight of the criterion / hazard $(j=1,2, \ldots, k)$;

$n_{\mathrm{j}}$ - score (points) associated with $j$ criterion;

$N$ - total number of assigned priorities.

The comparison can be provided by Fuller' triangle.

Another MCA method is Ranking method.

\subsection{Ranking method}

In ranking method (RM), every hazard under consideration is ranked in the order of the decision maker's preference. Regarding our problem of hazard assessment, the result will be a ranking or categorisation of hazard level to generate criterion values for each evaluation unit [10 \& 14]. Each hazard was weighted according to the estimated significance for causing more damage.

Using rank sum method the hazard weights were calculated as (3) and (4):

$$
\begin{gathered}
W_{\mathrm{j}}=\frac{b_{\mathrm{j}}}{\sum_{j=1}^{k} b_{\mathrm{j}}} \\
\sum_{j=1}^{k} b_{\mathrm{j}}=\frac{k}{2} \cdot(k+1)
\end{gathered}
$$

where:

$W_{\mathrm{j}}$ - weight of the criterion / hazard $(j=1,2, \ldots, k)$;

$k$ - is the number of hazard under consideration;

$b_{\mathrm{j}}$ - is the rank position of the hazard.

The less important criterion has position 1, the most important has position $n$ (number of hazards).

The purpose of the hazard weighting is to express the danger of each hazard relative to other hazard. The more dangerous hazard had the greater weight in the overall evaluation.

These MCA methods were applied in environmental hazard/risk assessment in Libya. 


\section{Environmental risk assessment in Libya}

\subsection{Analytic hierarchy process}

The first method for determining the most serious hazard facing Libya is Analytic hierarchy process. We use this process to determine the most dangerous hazard in Libya. We have considered the following hazards:

- Drought

- Volcano

- Earthquake

- Pollution

- Flood

- Tsunami

The first step in assessing the most dangerous hazard is to determine the impact affecting hazards seriousness on the basis of an analysis of existing studies and knowledge [8] from Libya. We have considered the following hazards' impacts in this study:

- Damage cost

- Frequency of occurrence

- Population exposed

- People killed

- Size of the affected area

The inverse ranking was applied to dividing these factors into classes the least important $=1$, next least important $=2$, etc. (Table 1$)$.

Table 1: The significance of the hazard impact

\begin{tabular}{|c|c|c|c|c|c|}
\hline \multirow{2}{*}{ Classes } & \multicolumn{5}{|c|}{ Hazard impact } \\
\cline { 2 - 6 } & $\begin{array}{c}\text { Damage cost } \\
(\text { Eur) }\end{array}$ & $\begin{array}{c}\text { Frequency } \\
\text { (in a year) }\end{array}$ & $\begin{array}{c}\text { Population } \\
\text { exposed } \\
\text { (number) }\end{array}$ & $\begin{array}{c}\text { People killed } \\
\text { (number) }\end{array}$ & $\begin{array}{c}\text { Size of the } \\
\text { affected area } \\
\left(\mathrm{km}^{2}\right)\end{array}$ \\
\hline 1 & $\left(0-10^{5}\right)$ & $(0-1)$ & $\left(0-10^{4}>\right.$ & $(0-100)$ & $\left(0-10^{3}\right)$ \\
\hline 2 & $\left.<10^{5}-10^{6}\right)$ & $<1-3>$ & $\left.<10^{4}-10^{5}\right)$ & $<100-500)$ & $\left.<10^{3}-5.10^{3}\right)$ \\
\hline 3 & $\left.<10^{6}-5^{*} 10^{6}\right)$ & $<3-4>$ & $\left.<10^{5}-20.10^{5}\right)$ & $<500-1000)$ & $\left.<5.10^{3}-10^{4}\right)$ \\
\hline 4 & $\left.<5^{*} 10^{6}-10^{7}\right)$ & $<4-5)$ & $\left.<20.10^{5}-10^{6}\right)$ & $<1000-2000)$ & $\left.<10^{4}-10^{5}\right)$ \\
\hline 5 & $<10^{7}-$ more) & $<5-$ more) & $<10^{6}-$ more) & $<2000-$ more) & $<10^{5}-$ more) \\
\hline
\end{tabular}


For each hazard was established matrix 5 x 5 - criteria x class $(1-5)$.

This matrix was completed with values from 1 to 5; depending to what class the hazard belongs in the following way: e.g. when number of people killed by hazard was 50 it belongs to class one; so to the line People killed and column "1" was written number 1; other values in this line are zero. Example of the completed matrix for drought hazard is in Table 2.

Table 2: Matrix of drought hazard according criteria

\begin{tabular}{|c|c|c|c|c|c|c|}
\hline \multirow{3}{*}{ Hazard } & \multirow{2}{*}{ Impact } & \multicolumn{5}{|c|}{ Classes } \\
\cline { 2 - 7 } & & 1 & 2 & 3 & 4 & 5 \\
\hline \multirow{5}{*}{ Drought } & Damage cost & 1 & 0 & 0 & 0 & 0 \\
\cline { 2 - 7 } & Frequency of occurrence & 0 & 0 & 3 & 0 & 0 \\
\cline { 2 - 7 } & Population exposed & 0 & 0 & 0 & 0 & 5 \\
\cline { 2 - 7 } & People killed & 1 & 0 & 0 & 0 & 0 \\
\cline { 2 - 7 } & Size of the affected area & 0 & 0 & 0 & 4 & 0 \\
\hline
\end{tabular}

The matrixes were completed for all selected environmental hazards. To determine the weight of each hazard was used AHP method, which was programmed in Microsoft Excel. In this way the matrixes were completed for all hazards.

Table 3 shows the results of the weight assessment by analytic hierarchy process method.

Table 3: Weight assessment by analytic hierarchy process

\begin{tabular}{|c|c|}
\hline Hazard & $\begin{array}{c}\text { Weight } \\
\left(W_{\mathrm{j}}\right)\end{array}$ \\
\hline Drought & 0.1861 \\
\hline Pollution & 0.1776 \\
\hline Flood & 0.1507 \\
\hline Earthquake & 0.1725 \\
\hline Tsunami & 0.1725 \\
\hline Volcano & 0.1405 \\
\hline Sum & 1.00 \\
\hline
\end{tabular}


From Table 3 is obvious that the drought is the most dangerous environmental hazard in Libya.

\subsection{Pairwise comparison}

The second method for determining the most serious hazard facing Libya is Pairwise comparison method. We have assessed the same hazards:

1 - Drought

2 - Volcano

3 - Earthquake

4 - Pollution

5 - Flood

6 - Tsunami

All pairs of hazard from 1 to 6 were mutually compared. Twenty people were asked to allocate the priority which hazard is the most dangerous for environment in Libya. They were: university staff - teachers (5 people); PhD students in civil engineering (5 people); $\mathrm{PhD}$ students in Economic (5); researchers (3); public (2).

The individual hazards were compared by Fuller's triangle in Figure 2 and the points were assigned to them. The points were counted and their sum is allocated to priority.

\begin{tabular}{|l|l|l|l|l|}
\hline 1 & 1 & 1 & 1 & 1 \\
2 & 3 & 4 & 5 & 6 \\
\hline \multirow{4}{*}{} & 2 & 2 & 2 & 2 \\
3 & 4 & 5 & 6 \\
\cline { 2 - 4 } & 3 & 3 & 3 \\
4 & 5 & 6 \\
\cline { 2 - 4 } & & 4 & 4 \\
& 5 & 6 \\
\cline { 3 - 4 } & &
\end{tabular}

Figure 2: Comparison of hazards with Fuller's triangle

The following results of the weight assessment in Table 4 were obtained by Pairwise comparison method. 
Table 4: The allocation of priority and weight assessment by Pairwise comparison

\begin{tabular}{|c|c|c|}
\hline Hazard & $\begin{array}{c}\text { Assigned priority } \\
(n)\end{array}$ & $\begin{array}{c}\text { Weight } \\
\left(W_{\mathrm{j}}\right)\end{array}$ \\
\hline Drought & 85 & 0.2833 \\
\hline Pollution & 80 & 0.2667 \\
\hline Flood & 75 & 0.2500 \\
\hline Earthquake & 33 & 0.1100 \\
\hline Tsunami & 20 & 0.0667 \\
\hline Volcano & 7 & 0.0233 \\
\hline Sum & 100 & 1.00 \\
\hline
\end{tabular}

The assessment by Pairwise comparison method shows that the drought has the highest score from the other hazards.

\subsection{Ranking method}

The next task is determining the hazards effecting Libya by Ranking method. The hazards used in this paper were selected due to their relevance in the study area. The straight ranking was applied to the same hazards as in previous case, $1^{\text {st }}$ is the most dangerous hazard and $6^{\text {st }}$ is the least dangerous hazard. Table 5 shows weight assessment by rank sum method where equations (3) and (4) were used.

Table 5: Weight assessment by rank sum method

\begin{tabular}{|c|c|c|c|}
\hline Hazard & Straight rank & $\begin{array}{c}\text { Position } \\
(k)\end{array}$ & $\begin{array}{c}\text { Weight } \\
\left(W_{\mathrm{j}}\right)\end{array}$ \\
\hline Drought & 1 & 6 & 0.2860 \\
\hline Pollution & 2 & 5 & 0.2380 \\
\hline Earthquake & 3 & 4 & 0.1900 \\
\hline Flood & 4 & 3 & 0.1430 \\
\hline Volcano & 5 & 2 & 0.0950 \\
\hline Tsunami & 6 & 1 & 0.0480 \\
\hline Sum & - & 21 & 1.00 \\
\hline
\end{tabular}

The results in Table 5 show drought as the most dangerous environmental hazard in Libya. 


\section{Results and discussions}

The first MCA method for determining the most serious hazards facing Libya was Analytic hierarchy process. To determine the weight of each hazard was used Visual Basic tool which was programmed in Microsoft Excel.

The second MCA method for determining the most serious hazard facing Libya was Pairwise comparison (PC). The total number of investigated assets determines the weight $W_{\mathrm{j}}$ of each hazard criteria, calculated according (1) and (2).

The third MCA method used was Ranking method (RM).

The final results are presented in Table 6 .

Table 6: Weight assessment of environmental hazards in Libya in \%

\begin{tabular}{|c|c|c|c|}
\hline Hazard & $\begin{array}{c}\text { AHP } \\
(\%)\end{array}$ & $\begin{array}{c}\text { PC } \\
(\%)\end{array}$ & $\begin{array}{c}\text { RM } \\
(\%)\end{array}$ \\
\hline Drought & 18.613 & 28.330 & 28.600 \\
\hline Pollution & 17.763 & 26.670 & 23.800 \\
\hline Flood & 15.068 & 25.000 & 14.300 \\
\hline Earthquake & 17.253 & 11.000 & 19.000 \\
\hline Tsunami & 17.253 & 6.670 & 9.500 \\
\hline Volcano & 14.050 & 2.330 & 4.800 \\
\hline Sum & 100 & 100 & 100 \\
\hline
\end{tabular}

The Multi-criteria analysis ends with a more or less stable ranking of the given alternatives and hence a recommendation as to which hazard mitigation measures should be preferred. Regarding our problem hazards assessment in Libya, the result is a ranking of hazard with regard to their risk level. The results from Table 6 show the drought as the most dangerous environmental hazard in Libya. It was proved by using all three MCA methods - AHP, PC, RM.

\section{Conclusion}

Environmental risks are consequent on manmade as well as natural hazards. The research focuses on the study of hazards assessment with results to reduce their impacts. Environmental risk assessment is an objective, scientific process of identifying and evaluating 
the adverse risks associated with a hazardous substance, activity, lifestyle or natural phenomenon that may detrimentally affect the environment and human health. It is processes to collect, organize, analyze and present scientific information to improve decision making. Multicriteria analysis methods as part of risk analysis [15] can help bring scientific data into environmental decisions.

Libya is witnessing of acceleration from the various aspects of development economic, industrial and social. For the success of development plans is important to formulate preventive strategies, plans and warning mechanisms. Risk assessment protects the lives and the devastation resulting from the natural as well as manmade hazards and disasters. The objective of this paper was to increase awareness of hazards and risks with aim to prevent their occurrence, to limit their impacts and minimize its losses.

The main goal of this paper was determined the most dangerous hazard effecting Libya country using multicriteria analysis methods - Analytic hierarchy process, Pairwise comparison, Ranking method. Quality of background information is very important to make good multicriteria decisions analysis.

The Analytic hierarchy process of Saaty's is a popular method for tackling MCA problems involving qualitative data, and has successfully been applied to many actual decision situations. Pairwise comparison is used in the decision-making process to form a reciprocal decision matrix, thus transforming qualitative data to crisp ratios and making the process simple and easy to handle. Ranking method is used to rank the every criterion under consideration in the order of the decision maker's preferences.

The obtained results indicate that the risk of drought is the greatest hazard threats Libya. This result helps managers to do steps to deal with this hazard.

\section{Acknowledgements}

The Centre was supported by the Slovak Research and Development Agency under the contract No. SUSPP-0007-09.

\section{References}

[1] MALCZEWSKI, J. (1999). Spatial multicriteria decision analysis. J.-C. Thill (Eds.). Multicriteria Decision Making and Analysis: A Geographic Information Sciences Approach. p. 11-48. Brookfield, VT: Ashgate Publishing.

[2] Atlas of Libya. (1985). Stockholm: Esselte Map Service.

[3] Geography. Libya. [cit. 18-01-2012]. http://geography.about.com/library/cia/blclibya.htm

[4] YAHAYA, S., AHMAD, N., ABDALLA, F.R. (2010). Multicriteria Analysis for Flood Vulnerable Areas in Hadejia-Jama'are River Basin, Nigeria. European Journal of Scientific Research. Vol. 42, No. 1, p. 71-83.

[5] SAATY, T.L. (1980). The Analytic Hierarchy Process. New York: McGraw-Hill.

[6] MAJERNÍK, M., VIRČÍKOVÁ, E., BOSÁK, M., CHOVANCOVÁ, J., HÚSKOVÁ, V. (2007). Environmental impact assessment. (in Slovak) Skalica: SVŠ. 
[7] Multi-criteria analysis: Manual. [cit. 17-01-2012]. http://www.eprints.lse.ac.uk

[8] KORYTÁROVÁ, J., ŠLEZINGR, M., UHMANNOVÁ, H. (2007). Determination of Potential Damage to Representatives of Real Estate Property in Areas Afflicted by Flooding. J. Hydrol. Hydromech., Vol. 55, No. 4, p. 282-28.

[9] SAATY, T.L. (2008). Decision making with the analytic hierarchy process. Int. J. Services Sciences. Vol. 1, No. 1, p.83-98.

[10] SAATY T.L. (1990). Multicriteria Decision Making: The Analytic Hierarchy Process. Pittsburgh: RWS Publications.

[11] ZELEŇÁKOVÁ M., GAŇOVÁ L., PURCZ P. (2011). Multi criteria analysis and risk analysis methods in flood risk assessment. In Global Climate Change and Biodiversity Conservation: 1st World Congress for Man and Nature. p. 173. Haridwar: Gurukula Kangri University.

[12] DENG, H. (1999). Multicriteria analysis with fuzzy pairwise comparison. International Journal of Approximate Reasoning. Vol. 21, p. 215-231.

[13] YALCIN, G. AND AKYUREK, Z. (2004). Analysing flood vulnerable areas with multricriteria evaluation. [cit. 10-02-2012].

http://proceedings.esri.com/library/userconf/proc04/docs/pap1097.pdf

[14] KORVINY, P. Theoretical basement of multicriteria analysis (in Czech). [cit. 15-03-2012]. http://korviny.cz/mca7/soubory/teorie_mca.pdf

[15] STN ISO 31000: (2011). Risk management. Principles and guidelines. SUTN. 